Douglas A. Hume

\title{
The Early Christian Community
}

\author{
A Narrative Analysis of Acts 2:41-47 and 4:32-35
}

[Die frühchristliche Gemeinde. Eine Erzählanalyse der Apostelgeschichte 2,41-47 und 4,32-35.]

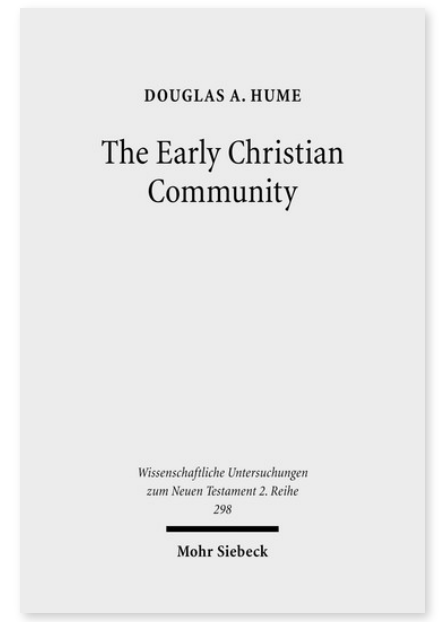

2011. XI, 176 Seiten. WUNT II 298

ISBN 978-3-16-151641-2

DOI 10.1628/978-3-16-151641-2

eBook PDF $64,00 €$

ISBN 978-3-16-150729-8

fadengeheftete Broschur $64,00 €$
Veröffentlicht auf Englisch.

Douglas A. Hume bietet eine ethische Lesart der Passagen, die die frühchristliche Gemeinde in der Apostelgeschichte beschreiben. Zuerst untersucht er methodologisch, wie zeitgenössische Wissenschaftler den Einfluss biblischer Erzählungen auf die Moralvorstellungen des Lesers einschätzen. Da in der Apostelgeschichte der Begriff der Freundschaft vielfach verwendet wird, untersucht der Autor dieses Wortfeld in griechisch-römischen philosophischen und literarischen Werken von Aristoteles, Plutarch, Diogenes Laertius und lamblichus. Danach zeigt er, wie Lukas seine Rede von der Freundschaft in den ersten beiden Sammelberichten der Apostelgeschichte benutzt. Die ethische Relecture von Apostelgeschichte 2,41-47 und 4,32-35 bezieht verschiedene Merkmale der Erzählkritik ein und fragt nach dem Gebrauch von Emotionen, der Perspektive und Charakterisierung, um beim Leser die Wahrnehmung von Gott, der frühchristlichen Gemeinde und anderer Eigenarten innerhalb des Lukasevangeliums zu formen.

Douglas A. Hume Born 1969; 2009 Ph.D. in New Testament is from Princeton Theological Seminary; currently Assistant Professor of Religion at Pfeiffer University in Misenheimer, North Carolina, USA.

Jetzt bestellen:

https://mohrsiebeck.com/buch/the-early-christian-community-9783161516412?no_cache=1

order@mohrsiebeck.com

Telefon: +49 (0)7071-923-17

Telefax: $+49(0) 7071-51104$ 